\title{
LOS PRINCIPALES RASGOS DE LA POLÍTICA EXTERIOR CHILENA ENTRE 1973 Y EL 2000
}

\author{
MANFRed WilheLMY, \\ ROBERTO DURÁN \\ Instituto de Ciencia Politica, Pontificia Universidad Católica de Chile
}

\begin{abstract}
Resumen
Siendo de carácter esencialmente ensayístico, este trabajo es una apretada síntesis referida a los principales hitos de la política exterior chilena durante el amplio período que abarca el último tramo del gobierno del Presidente Salvador Allende y los primeros diez años de la restauración democrática en Chile. El contraste entre distintos estilos diplomáticos, así como la incidencia de los factores económicos internos en las relaciones exteriores chilenas constituyen el núcleo analítico central de este estudio.
\end{abstract}

Abstract

This paper is mainly an essay, focused on the most important facts in chilean foreing policy during a period embracing the very latest phase of President Allende administration,all the authoritarian regime and the return to democracy at the beginning of the 90 's. The analysis about different diplomatic styles during this long period of time and the influence of Chilean domestic economy in foreign affairs are their most relevant issues.

PALABRAS CLAVE • Chile • Política Exterior • Economía Interna • Seguridad • Ideología

\section{PLANTEAMIENTO GENERAL}

La situación internacional de Chile ha cambiado radicalmente en los últimos treinta años. Entre los gobiernos de los Presidentes Salvador Allende y Ricardo Lagos, el país ha enfrentado serios retos a sus intereses básicos de seguridad, desarrollo y status en el sistema internacional; pero también se han abierto importantes oportunidades para avanzar hacia la consolidación de dichos intereses, especialmente a partir de 1990.

En el período 1973-2003, se han contrapuesto las más variadas posiciones políticas internas acerca de la definición y promoción de los intereses en la política exterior de nuestro país, insertadas en el contexto de cambios de gran magnitud en el escenario internacional global, los que de una u otra forma se han reflejado en Latinoamérica y en Chile.

Otro aspecto relevante observado durante esta etapa es una tendencia, de carácter sistemático pero sin llegar a ser una constante, cual es la atribución de características "emblemáticas" a ciertas políticas chilenas en la percepción de los actores oficiales que, una y otra vez, buscan un 
alto perfil externo, tanto como fuente de legitimación política como una manera abrir espacios de oportunidad para la diplomacia. Este estilo suele obligar a los actores a un elevado nivel de visibilidad política externa, con los consiguientes riesgos de sobreexposición e insuficiencia de los instrumentos con que cuentan las relaciones internacionales para alcanzar los objetivos definidos para cada materia o en cada período. En otras palabras, no hay un acopio o uso efectivo de recursos que estén a la altura de las exigencias de dicha sobreexposición, redundando en esfuerzos malogrados o en errores de apreciación sobre el entorno internacional. Entre los primeros mandatarios, han exhibido distintos grados de proclividad a elevar el perfil externo chileno los presidentes Allende, Pinochet y Lagos, cada uno dentro de su particular opción política y situación externa. En cambio, Aylwin de modo explícito y Frei en forma tácita, optaron por perfiles de actuación internacional más discretos.

\section{LA SITUACIÓN INICIAL}

En 1973, el sistema político chileno estaba sometido a tensiones extremas, hasta el punto que fueron minando su estructura, imposibilitando la capacidad de sus instituciones para canalizarlas. El ámbito de las relaciones exteriores no constituyó una excepción, por cuanto se encontraba en un punto crítico: aparentemente, el gobierno estaba dispuesto a asumir la opción de un realineamiento internacional, pero la viabilidad de este camino era poco probable, habida cuenta que no se avenía con la tendencia global, entonces consistente en un ostensible aminoramiento de tensiones entre las grandes potencias. En lo que toca a Chile, ya durante 1972 la Unión Soviética había dado señales de escepticismo frente a la estrategia allendista de conciliar objetivos revolucionarios con la institucionalidad vigente. Por otra parte, un realineamiento chileno hacia la órbita soviética hubiera generado a Moscú un problema serio con Estados Unidos, que podría haber perjudicado los esfuerzos a favor de la distensión entre las superpotencias. Anteriormente y sobre esto mismo, la República Popular China había advertido que el gobierno del Presidente Allende debía sostenerse más mediante esfuerzos internos y menos por la vía de la solidaridad internacional.

En el plano interno, el inminente derrumbe de las instituciones democráticas, la grave crisis económica y la creciente amenaza de golpe militar, configuraban un conjunto de condiciones adversas para el desarrollo de la diplomacia, cuyos desafíos eran sustentar la defensa y promoción de los intereses políticos, de seguridad, económico-sociales y culturales del gobierno de Allende ante los interlocutores externos. Una de las paradojas de esta diplomacia es que ella constituía un instrumento de corte tradicional al servicio de una política de orientación revolucionaria. Esta difícil situación era una causa adicional de tensión, la que algunos actores oficiales trataban de enfrentar a través de la utilización de canales extra-diplomáticos de comunicación con los gobiernos y otros actores cercanos a la Unidad Popular. Esta situación terminó abruptamente con el golpe militar del 11 de septiembre de 1973.

La política exterior del régimen militar inauguró un deliberado estilo de confrontación ideológica con el bloque soviético y sus aliados, haciendo del anticomunismo el eje central de su postura internacional. La mantención de relaciones diplomáticas con la República Popular China fue una excepción -justificada desde el punto de vista del principio de no-intervención-, aparentemente motivada por consideraciones de Realpolitik por ambas partes. La militancia ideológica del gobierno, sus prácticas represivas y su rápido alejamiento del objetivo inicialmente declarado de restau- 
rar la institucionalidad democrática quebrantada, generó importantes tensiones con las principales democracias occidentales, sumiendo al régimen en una crisis de falta de legitimidad externa, rasgo que sería una constante de la política exterior de dicho período presidencial. A partir de 1974, la evolución de la Junta Militar de Gobierno hacia un sistema de dictadura militar de largo plazo bajo el liderato del general Augusto Pinochet, quien sistemáticamente consolidó y expandió su poder personal, contribuyó a complicar la situación externa del país.

\section{LOS AÑOS SETENTA}

En las precarias condiciones políticas en que se desenvolvió el régimen autoritario, surge la interrogante acerca de sus bases de sustentación. Obviamente, éste tuvo importantes bases de apoyo interno en los grupos que se habían opuesto al gobierno de la Unidad Popular, los cuales en una primera etapa incluyeron sectores democráticos que, en atención al cambio antes señalado, pronto pasarían a la oposición, con las dificultades que entonces implicaba el constituirse como tal durante los restantes dos tercios de los años setenta.

En el plano externo, las administraciones republicanas de los presidentes Richard Nixon y Gerald Ford prestaron valioso respaldo inicial al gobierno militar. En el ámbito vecinal, el gobierno se manejó pragmáticamente para disminuir los frentes de vulnerabilidad percibidos en el entorno. Por esta razón, buscó un entendimiento con Bolivia, se acercó inicialmente (antes de la crisis del Canal Beagle e islas adyacentes) al gobierno militar argentino y acrecentó sus vínculos con la dictadura brasileña.

Dicho pragmatismo fue menos exitoso en los nexos chileno-peruanos. Actores políticos civiles y militares de corte nacionalista -muchos de ellos allegados al Presidente Velasco Alvarado durante los dos primeros tercios de los años setenta-, estimaron propicia la oportunidad para estimular un conflicto bélico con Chile, al tenor del centenario de la Guerra del Pacífico. Aunque ello implicó un despliegue confrontacional no menor, el hipotético problema fue contenido y posteriormente desbaratado por medio de contactos directos entre militares chilenos y peruanos de alto rango, con la anuencia de sus respectivos Jefes de Estado. Esta peculiar "diplomacia castrense" no tendría el mismo resultado tiempo después, con motivo de las complejas negociaciones chileno-argentinas por el diferendo en la región austral.

En materia económica, se adoptó una política de "shock", destinada a forzar la recuperación de los equilibrios macroeconómicos, empujando al mismo tiempo al comercio exterior hacia una apertura unilateral de importaciones y fuerte promoción de exportaciones. La promulgación e inmediata ejecución del Decreto-Ley 600 en 1974 liberalizó el régimen de inversiones extranjeras, lo cual contrariaba la filosofía nacional-estatista del Pacto Andino, institución en la que Chile jugó un rol importante en los años de los Presidentes Frei Montalva y Allende. Dichas discrepancias obligaron al retiro de Chile de esa entidad en 1976. Por otro lado, se inició una política de desregulaciones y privatizaciones en diversos ámbitos y sectores productivos de la economía nacional, originándose una singular división de posiciones frente a la situación chilena al interior de los países desarrollados. Mientras algunos de éstos observaban expectantes estos drásticos cambios, otros se inclinaban por denunciar el costo político y social que significaba un régimen autoritario. 
Al interior del país, mientras una parte importante de los sectores político-partidistas mantenían su reticencia hacia el gobierno militar y proponían un pronto término del régimen y su reemplazo por una fórmula política más acorde con sus preferencias, diversos actores económicos -y posteriormente grupos políticos vinculados a éstos- vieron en las políticas económicas de la nueva administración una promesa para superar el estancamiento económico y la persistente hiperinflación, así como el surgimiento de perspectivas comerciales auspiciosas y nuevas oportunidades de inversión.

La deslegitimación política del régimen militar se reforzó como consecuencia del atentado terrorista contra el ex Ministro de Defensa Nacional y ex Canciller Orlando Letelier y su asistente Ronni Moffit en Washington D.C., en septiembre de 1976. La gravedad de este hecho se profundizó al identificarse la participación de agentes enviados por la Dirección de Inteligencia Nacional (DINA), entidad encargada de supervisar la seguridad del gobierno chileno. Esta situación afectó seriamente las relaciones con los Estados Unidos, en especial durante la administración del Presidente Carter, la cual puso de relieve en su política exterior el tema de la promoción y respeto de los derechos humanos y de la democracia, particularmente en América Latina. Así, el gobierno norteamericano se alejaba de las preferencias sustentadas por la anterior administración republicana.

La política exterior del régimen militar tuvo implicaciones respecto de ciertos estilos tradicionales de la Cancillería. Durante años, lo central de la estrategia exterior del régimen estuvo imbuido de una compleja combinación de "nacionalismo" y "realismo", plasmando una postura que intentaba realzar el estilo bilateral, en detrimento del tradicional multilateralismo de la diplomacia chilena. En esta perspectiva, la cooperación y la integración regional, así como el multilateralismo mundial eran instancias que giraban al tenor de opciones ideológicas, casi todas contrapuestas con los principios de la política externa del sistema. De esta forma, para el gobierno militar el multilateralismo trasuntaba una visión utópica de las relaciones internacionales, característica que convertía a los organismos multilaterales en instancias sensibles a ideologías, la mayoría de éstas del todo incompatibles con la opción "occidentalista" del nuevo gobierno chileno.

En rigor, tanto el multilateralismo global como el interamericano estuvieron lejos de ser gratos al régimen militar, del mismo modo que éste tampoco concitaba simpatía alguna en dichos ámbitos. Ya en la Asamblea General de Naciones Unidas a fines del 73 hay un primer informe de la Comisión de Derechos Humanos de Ginebra, cuyo diagnóstico y recomendaciones fueron abrumadoramente respaldadas por la mayoría de los países representados en esa oportunidad. Durante las siguientes 15 Asambleas Generales de la Organización de las Naciones Unidas se registraron resultados similares, predisponiendo como "profecía auto-cumplida" al régimen militar contra la ONU y contra el multilateralismo global en general. No fue muy distinto el caso en el sistema interamericano, habida cuenta que la Comisión de Derechos Humanos de la Organización de Estados Americanos evacuó informes parecidos a su homónima en Ginebra entre 1975 y 1978.

Al tenor de una serie de significativos cuestionamientos, investigaciones y condenas en la Comisión de Derechos Humanos de las Naciones Unidas en Ginebra, y las sucesivas condenas que recibiera el régimen militar en las Asambleas Generales de la Organización al terminar el año 1973, el gobierno chileno reaccionó convocando a una "Consulta Nacional" a mediados de 1978. En una especie de plebiscito, el país debía decidir entre el respeto a la soberanía nacional y los dictámenes de las organizaciones mundiales. La realización de dicho acto, sin registros electora- 
les (los existentes hasta el golde de Estado habían sido destruidos), ni garantías políticas y jurídicas a los eventuales disidentes, privó de efecto legitimador a la previsible victoria oficial.

Entre los años 1977 y 1978 emerge una aguda crisis diplomática con Argentina. El laudo arbitral británico fue favorable a Chile en la vieja disputa territorial y marítima de la zona austral del Canal Beagle. En una decisión sin precedentes, Argentina declinó aceptarlo y lo declaró de "nulidad insanable", hecho que probablemente constituyó el reto más serio a los intereses de seguridad del país bajo el régimen militar. Paradojalmente, el desafío no provino de alguno de los declarados enemigos externos, sino de otro régimen burocrático-autoritario, con el cual compartían una percepción ideológica anti-marxista. Agotadas las instancias de negociaciones civiles y militares, se vivió un estado de guerra en diciembre de 1978, que estuvo a punto de llevar al estallido de hostilidades en la región austral. Gestiones de última hora para desactivarla llevaron a las partes a aceptar la mediación del Vaticano a través de un enviado especial, el Cardenal Antonio Samoré. Ello evitó la guerra y, tras arduos esfuerzos del mediador y de las partes, se abrió una nueva etapa en los vínculos bilaterales como consecuencia del Tratado de Paz y Amistad de 1984.

En otro ámbito, el confuso "incidente filipino" (consistente en la abrupta anulación de la invitación del Presidente de Filipinas, Ferdinando Marcos, al general Augusto Pinochet a visitar su país, cuando éste ya estaba en viaje a Manila), confirmó la debilidad de la posición política internacional del gobierno militar, dejando en claro que un acercamiento a los países del Sudeste asiático difícilmente ayudaría en el plano político-diplomático, aunque éste suscitara mayor interés en el plano comercial.

\section{LA CRISIS DE LOS AÑOS OCHENTA}

La crisis cambiaria y financiera que sigue a la devaluación del peso en el primer tercio de los años ochenta (una vez que el desequilibrio de las cuentas externas forzó el fin de la política de cambio fijo a \$39 por dólar), implicó el colapso de los grupos económicos altamente endeudados, lo que dio inicio a una recesión económica profunda, que duraría hasta mediados de esa década.

En cuanto al ámbito externo, Chile siguió el camino de México y otros países de la región. Las autoridades de entonces, imposibilitadas de hacer frente al calendario de vencimientos en la deuda externa, se vieron compelidas a solicitar sucesivas renegociaciones de sus obligaciones -mayoritariamente contraídas por el sector privado- a fin de evitar una moratoria generalizada, que, además, habría recaído en la capacidad de satisfacer las necesidades de importación. En esta difícil crisis se identificó y se aprovechó una interesante oportunidad, esto es, la utilización de una novedosa fórmula de canje de deuda por capital, la cual sirvió tanto para aligerar su servicio como para estimular la inversión extranjera, adelantando así una cierta recuperación.

Por cuanto una trayectoria económica de recuperación ascendente era esencial para las perspectivas de consolidación del régimen autoritario (que recientemente había ganado el plebiscito constitucional de 1980, y con ello un período presidencial de ocho años para el general Augusto Pinochet), la persistente recesión representaba una grave amenaza. De hecho, ésta facilitó la reagrupación de la oposición, dando lugar a masivas protestas nacionales a partir de 1983. Esta situación permitió la articulación de demandas políticas opositoras, creándose en 1984 un Acuerdo Nacional (que en su momento abarcó a parte importante de la derecha democrática), el cual 
sería el germen de lo que posteriormente sería la Concertación de Partidos por la Democracia. Frente a este cuadro, el gobierno militar elevó la represión interna, ahondando su ya minusválida imagen externa.

Con el gobierno militar a la defensiva en esos años, se planteó la posibilidad de optar por abandonar, o al menos "diluir", la política económica de libre mercado, propiciándose fórmulas más intervencionistas y proteccionistas en la economía, con ciertas connotaciones populistas. Entre los protagonistas políticos de este viraje destacaron el Ministro del Interior Sergio Onofre Jarpa, mientras otros ministros "no-Chicago" en las carteras económicas intentaban -con magros resultados- revertir la crisis recesiva. Así, en las pugnas internas gubernamentales los sectores neoliberales volvieron a gozar del favor del general Augusto Pinochet, retornándose a una ortodoxia que se consolida durante la gestión del Ministro de Hacienda Hernán Büchi. Retrospectivamente, se intuye cierta vacilación de Pinochet en el curso de la prolongada crisis. Pero la radicalización de las protestas, con la consiguiente deserción de ellas de una parte de la oposición moderada, y el frustrado atentado contra Pinochet en septiembre de 1986, dividieron a la oposición y ayudaron al oficialismo a recuperar cierta cohesión.

Durante la segunda administración del Presidente Ronald Reagan habrá un cambio de fondo en los vínculos diplomáticos chileno-norteamericanos. Desde luego, el volumen y los alcances de las protestas desde 1983 en adelante empiezan a afectar la percepción de sectores relevantes de la clase política norteamericana, muy en especial en el Congreso. De esta manera, más allá de la inicial comprensión manifestada por el gobierno estadounidense hacia el régimen militar -muy en especial por la implantación del modelo de mercado que ya empezaba a proyectar los primeros resultados positivos a partir de 1984-1985-, aún más fuerte fue la presión de los sectores liberales del Congreso, de la prensa y de grupos influyentes de la dirigencia política norteamericana. Al iniciarse la segunda administración de la misma Presidencia elegida en 1980, el gobierno y la diplomacia de los Estados Unidos procedieron a enfriar fuertemente su relación con el gobierno chileno desde 1985 en adelante.

La representación diplomática de Estados Unidos en Chile, en conjunto con la de varios países miembros de la Comunidad Europea, asumen una postura abierta y decididamente crítica frente a la realidad política chilena, presionando por la restitución de los derechos políticos de las personas, junto con promover las condiciones para un pronto retorno al régimen democrático.

En este mismo orden de cosas, otro factor que afectó de manera adversa a la política exterior del régimen militar fue la tendencia regional a la democratización de los regímenes políticos latinoamericanos en los años ochenta. Fueron los años de la vuelta a la democracia en países importantes como Argentina, Brasil y Perú. Si bien estas transiciones ocurrieron en el conocido contexto de crisis económica ( que combinaba una aguda recesión interna y la imposibilidad de servir la deuda externa), el caso chileno no podía sino percibirse como anómalo en el marco de la evolución latinoamericana.

Respecto de lo que acontecía entre las grandes potencias, si bien el gobierno militar auscultó como favorable la situación generada por la expansión de la Unión Soviética en Afganistán y se sintió alentado por el marcado anti-comunismo del Presidente norteamericano Ronald Reagan a partir de 1980, ello sería un lapso de tiempo sumamente corto. Como lo anticipamos, durante la 
segunda administración de Reagan se renovaron las presiones en materia de derechos humanos y en favor de una transición hacia un sistema democrático-representativo. Para los Estados Unidos tal postura era importante, por cuanto constituía una triunfal carta político-ideológica en el contexto del inminente resquebrajamiento del "imperio del mal", es decir, del socialismo real de esos años. La política exterior norteamericana volvería a decepcionar las expectativas del régimen militar chileno.

\section{POLITICA INTERNACIONAL DE LA TRANSICIÓN}

El plebiscito electoral de 1988, convocado bajo los términos de la Constitución Política de 1980, con el fin declarado de lograr la "proyección del régimen", contribuyó decisivamente a cambiar la situación política externa del país. La decisión estratégica de la oposición democrática de aceptar las reglas del juego establecidas por el gobierno militar, en el entendido que así se podía lograr su derrota política, fue una arriesgada, pero exitosa apuesta que libró al sistema político de un nuevo quiebre institucional, abriendo el camino de una entrega ordenada del poder a la oposición democrática.

En el período plebiscitario y de la campaña presidencial posterior a la victoria del "No", la oposición, a través de la Concertación de Partidos por la Democracia, se consolidó como una coalición viable, que combinó sus bases internas con importantes apoyos externos, tanto de gobiernos, partidos políticos y entidades cercanas a estos, diversas ONGs, influyentes centros de estudio y figuras del mundo académico. Los medios de comunicación internacionales desempeñaron un papel central en la articulación de este espectro amplio de actores.

La política internacional de la transición constituyó un caso significativo del estilo marcadamente transnacional en el estilo de las relaciones exteriores. En adelante, los procesos políticos regionales ejercerían gran influencia en la definición de las prioridades de la política exterior, lo que afectaría el uso de determinados instrumentos políticos y diplomáticos, particularmente en el ámbito del multilateralismo. En Chile, varias instituciones académicas y centros de estudio jugaron un rol relevante en la constitución de grupos de trabajo que aportarían antecedentes analíticos y prácticos para la confección de la política exterior de los gobiernos de la transición. Destacados actores de dicha política, como José Miguel Insulza, Heraldo Muñoz, Juan Somavía, Juan Gabriel Valdés, Carlos Portales y Alberto van Klaveren hicieron aportes esenciales desde la fase programática, basándose en sus relevantes conocimientos especializados. Posteriormente, varios de ellos asumirían altas responsabilidades oficiales.

La negociación de un "paquete" de cincuenta y cuatro reformas constitucionales y su aprobación por el electorado dio credibilidad a la tesis de la factibilidad de la restauración democrática por la vía de acuerdos negociados. En la medida en que el oficialismo fue incapaz de levantar una candidatura presidencial con posibilidades reales de ganar electoralmente a la Concertación, quedó abierto el camino para la continuación de la transición a través de un mandatario civil de larga trayectoria política, con el apoyo de la oposición democrática al régimen militar. 


\section{GOBIERNO DE PATRICIO AYLWIN (1990-1994)}

La política exterior de este período centró sus esfuerzos en la "reinserción internacional" del país. Aunque algunos analistas, entre quienes destaca Heraldo Muñoz, han sostenido que en el período anterior el país había estado aislado, el término induce a cierta confusión. Por cierto, durante el régimen militar el gobierno chileno estuvo fuertemente impugnado por una multiplicidad de actores internacionales, algo que desde el entonces punto de vista oficial se percibió como un asedio externo, mientras que desde la oposición se auscultaba como una manifestación de solidaridad política. Tal configuración difiere, a nuestro juicio, de una situación de aislamiento, a menos que este concepto se redefina (como hizo Muñoz) como una situación equivalente al fracaso de una política exterior.

Desde la perspectiva que sugerimos, la estrategia de la "reinserción internacional" durante la administración Aylwin consistió, entre otras, en una positiva aceptación externa del proceso de recuperación de las tradiciones democráticas y el comienzo de la tarea de enfrentar las consecuencias políticas, jurídicas y humanitarias del período autoritario. Ello puso fin, en lo esencial, a la situación de impugnación que gravitaba sobre el gobierno anterior, disminuyendo la vulnerabilidad política internacional del país, permitiendo al mismo tiempo recuperar gradualmente una mayor presencia e influencia en los niveles global, regional y bilateral de su política exterior.

En América Latina, la política del Presidente Aylwin reactivó el papel de la diplomacia chilena en foros multilaterales como la OEA, además de incorporarse a las nuevas instancias de concertación política regional, principalmente el Grupo de Río. Es significativo observar que el compromiso hemisférico de "Promoción y defensa de la democracia representativa" asumido en el marco de la OEA, se acordara precisamente en Santiago en 1991. Con todo, Aylwin procuró evitar que esta política se percibiera como una reivindicación de liderazgo político por parte de su gobierno en la región. Por otro lado, el gobierno negoció exitosamente acuerdos de libre comercio y de complementación económica con México, Bolivia, Colombia, Venezuela y Argentina.

En el plano de los problemas limítrofes, se dio prioridad a la identificación de materias pendientes con Perú (especialmente las cláusulas de ejecución pendientes del Tratado de 1929), Bolivia (varios temas, sin aceptar entre ellos la situación de mediterraneidad boliviana) y Argentina (Laguna del Desierto, Campos de Hielo Sur y otros). Además de referirse a mutuos intereses de seguridad, con la solución de antiguas disputas se trataba de despejar el camino para iniciativas de cooperación, entre los que destacaban diversos planes de integración vial y energética.

Frente a Europa, aparte de los objetivos de normalización política ya aludidos, el gobierno de Aylwin logró un primer acuerdo marco de cooperación de cuarta generación con la Comunidad Europea, el primero de esta naturaleza negociado por un país fuera de la órbita directa de intereses europeos, aunque posteriormente se firmaron instrumentos similares con varios países latinoamericanos. De esta manera, se abrió el camino para otras iniciativas, que culminarían con el acuerdo de cooperación y libre comercio con la Unión Europea el año 2002.

Los vínculos bilaterales con los Estados Unidos de esos años iniciaron un nuevo estilo en el ámbito de la cooperación militar. Ésta se mantendría y profundizaría con los posteriores gobiernos de la Concertación. Una vez reinstaurado el régimen democrático-representativo en nuestro país, las 
distintas entidades de la defensa norteamericana se empeñaron en reconstituir las desencantadas relaciones bilaterales con Chile en el plano militar, sumamente resquebrajadas durante el período 1975-1990. El incentivo de esta remozada interacción tenía dos propósitos. Primero, se trataba de fomentar una buena y respetuosa relación civil-militar. Tal era también el propósito de las instituciones de la defensa y los grupos políticos chilenos, por cuanto la restauración de la democracia ponía a un mismo nivel de colaboración a militares y civiles. Estos esfuerzos contaron con el apoyo financiero de importantes fundaciones académicas de los Estados Unidos. En segundo lugar, hubo acercamientos institucionales propiamente tales, no todos con los mismos resultados. Los logros de esas aproximaciones fueron variables, pero lo destacable es que dieron cuenta de un cambio substancial en la relación bilateral chileno-norteamericana. Hay que tener en cuenta que la recomposición de las relaciones bilaterales en el plano militar guarda conexión con el ritmo en que operan los vínculos políticos. Aunque estos últimos fueron especialmente propicios en el momento en que se redemocratiza políticamente el país, la demora en el plano de las Fuerzas Armadas se debió, en gran medida, a la predisposición que imperaba en el ánimo de las instituciones militares chilenas a principios de la década anterior. Para nadie es desconocida que la opción asumida por el gobierno y la diplomacia norteamericanas respecto del régimen militar chileno -en especial en sus últimos cuatro años- fue de una clara oposición, originando entonces en la oficialidad de sus instituciones armadas una clara animadversión hacia los Estados Unidos.

En lo concerniente a las relaciones comerciales, el gobierno recogió la propuesta estadounidense de negociar un área de libre comercio "desde Alaska a Tierra del Fuego", aunque muy luego quedaría de manifiesto que el avance de un proyecto de esta magnitud requeriría de un tiempo más prolongado. Un par de meses después de anunciar el entonces Presidente George Bush I su "Iniciativa para las Américas" a mediados de 1990, la diplomacia chilena inició una ambiciosa etapa de contactos y negociaciones con el Departamento de Estado, tendientes a incorporar a nuestro país al Tratado NAFTA. Tal estrategia se fundamentaba en el prestigio internacional de la transición chilena al régimen político democrático, pero sobre todo en el peso sustentado por la "imagen emblemática del modelo económico chileno", al cual una proporción importante de economías latinoamericanas intentaba emular teniendo a la vista una tasa promedio de crecimiento en torno al 6,5\% entre 1984 y 1996 . Pero la imagen exitosa del modelo y la fuerza del impulso diplomático de nuestro país no fueron suficientes para incorporarlo al Tratado NAFTA entre 1994 y 1995, durante la administración del Presidente Eduardo Frei R-T. La falta de experiencia en el manejo de "lobbies" y una aproximación errada a los círculos de influencia en el gobierno y en el Congreso norteamericanos mermaron los intentos de Chile.

No obstante, la impronta expansiva del comercio exterior abrieron las negociaciones con los socios del NAFTA. Así, en 1992 se establece un Tratado de Libre Comercio con México y más tarde, en 1995, otro similar con Canadá, reforzando el marco del "regionalismo abierto". Este último constituyó la impronta de la diplomacia chilena durante los años noventa y ha seguido siendo la tónica de su estrategia multilateral durante el primer tercio de la década actual.

En el ámbito del Asia Pacífico, el gobierno se interesó, especialmente, en elevar el nivel de las relaciones con los países del Sudeste asiático, particularmente con Malasia. De esta forma, el país diversificaba ostensiblemente sus relaciones exteriores, intentando obtener el apoyo asiático para el ingreso de Chile en el Foro de Cooperación Económica Asia Pacífico, APEC. Era conocida 
en este campo la reticencia de algunos miembros de dicha entidad, como fue en su momento el caso de Australia. En esta dirección se inscribe la escasa voluntad manifestada por los Estados Unidos a las pretensiones chilenas, donde, por lo demás, el tema era altamente controvertido en los distintos planos en que se desenvuelve la burocracia de la política exterior norteamericana. Luego de una intensa campaña, el propósito chileno se alcanzó en la Cumbre APEC de Blake Island (Seattle, 1993), la cual abrió sus puertas a los grupos de trabajo de la institución y aseguró la plena incorporación de nuestro país a partir de la Cumbre de Bogor, Indonesia, en 1994. Cabe señalar que esta política se despliega en el contexto económico-comercial de la primera mitad de los años noventa, período que corresponde en plenitud al denominado "milagro asiático".

Las líneas de acción mencionadas se inscribieron en el marco de una decisión estratégica cimentada en el modelo socio-económico de mercado, en el entendido que así se fortalecía y consolidaba el crecimiento económico de Chile. De esa manera, las políticas y procedimientos macroeconómicos eran congruentes con objetivos tales como el complementar las falencias originadas por la escasa capacidad de ahorro interno de la economía. De allí cuán indispensable era atraer nuevas y cuantiosas inversiones extranjeras, tanto en las diferentes áreas productivas como en el sector financiero. Consistente con lo anterior, el gobierno continuó con una estrategia comercial externa basada en la diversificación de los mercados de exportación. Es innegable que tal maniobra tuvo resultados tangibles, lo cual posibilitó el ingreso sostenido y recurrente de divisas a nuestra economía, factor que incidiría en el notorio crecimiento del PIB chileno durante los dos primeros tercios de los años noventa. Esa misma estrategia comprendía la puesta en marcha de correctivos socio-económicos, los cuales propendían a una mayor equidad en la distribución de los frutos del crecimiento, disminuyendo el volumen nominal de la pobreza absoluta, la que por esos años congregaba a un alto porcentaje de la población.

Sin embargo, hubo insuficiencias y carencias en la política exterior durante ese período. Entre otras hubo un déficit de coordinación entre actores y niveles decisionales de la Cancillería, además de una situación similar entre éstos y otros sectores gubernamentales. Las disputas burocrático-decisionales en torno a determinadas negociaciones comerciales evidenciaron carencias profesionales no menores y prueba de ello fueron las infructuosas conversaciones entre Chile y los Estados Unidos respecto del ingreso de nuestro país al Tratado NAFTA. Esta anomalía se verificó durante las dos primeras administraciones de la Concertación.

También destacan las complicaciones originadas por la interferencia de criterios partidistas en la conducción de la política exterior, como fuera el caso del asilo brindado por la Embajada chilena en Moscú al ex gobernante de la República Democrática Alemana, Erich Honecker. Junto con generar agrias disputas políticas internas, esta situación causó fricciones en las relaciones bilaterales chileno-alemanas.

\section{EL GOBIERNO DE EDUARDO FREI R.T. (1994-2000)}

El segundo gobierno de la Concertación diseñó su política exterior en el entendido que la reinserción internacional del país se había logrado sustancialmente. La idea de una "diplomacia para el desarrollo" del gobierno del Presidente Eduardo Frei Ruiz-Tagle puso de relieve una mayor gravitación de la política exterior chilena en torno a los intereses económico-comerciales, por cuanto la eco- 
nomía chilena se ubicaba crecientemente en un contexto de interdependencia global y regional. Por otro lado, durante esta administración se propugnó una mayor proximidad entre el proceso político interno y la diplomacia, en sus aspectos políticos y económico-comerciales.

En materia de acuerdos económico-comerciales, el gobierno procuró conciliar múltiples iniciativas, buscando alcanzar equilibrio y diversificación comercial a través de asociaciones con diversas regiones y subregiones en América Latina (particularmente con el MERCOSUR), con Norteamérica, con la Unión Europea y con la región Asia-Pacífico.

Cabe acotar que el particularismo es un rasgo de la diplomacia multilateral chilena durante este período, especialmente entre 1994 y 1996. En esos años, para la diplomacia chilena no eran organizacionalmente homologables los debates y conclusiones en las instancias políticas (las reuniones anuales del Grupo de Río y las Reuniones/Cumbre de Presidentes Latinoamericanos) y los órganos de cooperación comercial (el Sistema Económico Latinoamericano, SELA; la Asociación Latinoamericana de Integración, ALADI y el MERCOSUR), por cuanto cada uno de estos tienen sus propias prioridades institucionales. Pero por sobre todo no eran homologables fácticamente, en la medida en que cada uno genera procesos que no son extra-polables ni comparables. Con ello no se quería afirmar que la concertación política y la cooperación regional estuvieran desprovistas de un sentido de globalidad, sin embargo, ésta era perceptible en el mediano y/o largo plazos. Lo que se sostiene es que ambas estaban imbuidas de una dinámica autónoma, reforzada por las particularidades institucionales. En suma, había que entenderlas como "regímenes internacionales", en su acepción genérica.

A fines de 1994, el Presidente Frei participó por primera vez en una Cumbre de Líderes de APEC en Bogor, Indonesia. En dicha cita, los líderes de los países de la región acordaron las denominadas "metas de Bogor", referidas a realzar el libre comercio entre las economías de APEC, objetivo fijado para las economías desarrolladas el año 2010 y para las que estaban en desarrollo el 2020. No obstante su condición de economía en desarrollo, el gobierno chileno manifestó su compromiso de acogerse a la meta del año 2010, quizás para acentuar su decisión de asimilar su status al de economías con mayor desarrollo mediante una vigorosa apertura de ella. En adelante, Chile se perfilaría como un activo participante en APEC, aunque el fuerte embate de la crisis asiática (1997-1999) restó dinamismo a la integración del Pacífico y tendría después repercusiones económicas internas importantes, marcando el comienzo de la larga fase de desaceleración del crecimiento que afecta al país hasta bien entrado el primer tercio de la primera década del nuevo siglo. Con todo, el Canciller de entonces, José Miguel Insulza, tuvo la visión de abogar por la continuidad del esfuerzo político-económico chileno en Asia-Pacífico, y en particular en APEC, arguyendo que se trataba de una política de largo plazo, orientada a solventar los intereses permanentes del país. En momentos que Chile se apresta para conducir el foro APEC entre fines del 2003 a noviembre del 2004, está claro que el criterio del Canciller de la época fue acertado.

Frente a Norteamérica, la opción del gobierno fue la proyectada incorporación al NAFTA en virtud de la invitación en ese sentido formulada por los tres miembros de dicha área económica en el marco de la Cumbre Hemisférica de Miami, en diciembre de 1994. Mas, la falta de autoridad negociadora especial ("fast track") del gobierno de Estados Unidos en la práctica imposibilitó avanzar en términos efectivos. El Presidente Clinton retomaría el tema en el primer año del mandato presidencial de Ricardo Lagos, proponiendo la vía bilateral y apostando, exitosamente, a una 
eventual concesión legislativa de facultades especiales ("Trade Promotion Authority"). Sin embargo, hay que recordar que subsisten temas relevantes por afiatar en la relación chileno-norteamericana, particularmente frente a la ejecución de un acuerdo bilateral de libre comercio. Entre estos figura el tópico ecológico / medio-ambiental. Por lo pronto, la legislación chilena en este acápite está a medio camino de la estadounidense, en especial en el cumplimiento de diversos protocolos dictaminados en el Tratado de la Organización Mundial del Comercio, suscrito en Marrakech, en 1995. Algunos han sido cumplidos por Chile, como queda de manifiesto en el TLC con Canadá de 1995 y en otras inversiones de capitales extranjeros, muy rigurosamente desde 1996. Ha sido el caso, por ejemplo, de todas y de cada una de las cuantiosas inversiones extranjeras en enormes yacimientos de cobre en el Norte Grande, procedimiento similar llevado a cabo en las inversiones forestales, en la piscicultura y en las actividades químico-mineras en las regiones XI y XII. Pero seguía y sigue ausente una clarificación sobre los criterios globales de la legislación chilena en esta materia.

También en este período la diplomacia multilateral de Chile tuvo una especial satisfacción, con evidentes implicaciones en el status internacional del país. Después de varios años, Chile se incorporó, nuevamente, en el Consejo de Seguridad de la ONU. Fue imprescindible y estratégico asumir una posición clara y fundada sobre este punto. Fue indispensable, por cuanto el reingreso de Chile al Consejo de Seguridad, necesariamente implicó re-perfilar el ámbito de lo multilateral entre las prioridades de nuestra política exterior, factor que estuvo presente durante el resto de los años noventa. Fue también estratégico, en la medida en que la diplomacia chilena no pudo sustraerse de un proceso cuyo objetivo consistía en asegurar para Naciones Unidas un mayor y/ o un mejor logro de objetivos políticos concretos, tanto en el plano de las decisiones de la Asamblea General (en materia de recursos y políticas presupuestarias), como en el de las decisiones emanadas del Consejo de Seguridad (especialmente en lo concerniente a las nuevas estrategias de "mantención" y/o "imposición" de la paz).

En el ámbito latinoamericano, se continuó el acercamiento con los países del MERCOSUR. La fórmula escogida -un acuerdo de asociación- permitió soslayar los obstáculos que implicaba una incorporación plena del país. La no-viabilidad de una integración completa de Chile era sustentable al tenor de notorias diferencias en políticas arancelarias y, en menor medida, al tratamiento de ciertas inversiones extranjeras. Asimismo, la postura proteccionista del gobierno respecto del sector agropecuario y de determinadas actividades agro-industriales alejaba la posibilidad de que ello ocurriera.

Pocos hechos tuvieron incidencia de proporciones como los efectos internos y externos producidos por la detención del general Augusto Pinochet en Londres, a fines de 1998. Por lo pronto, muy poco pudieron hacer la diplomacia, así como determinadas entidades partidarias y actores políticos chilenos frente a una situación de hecho, al menos durante los primeros meses de la prolongada permanencia de Pinochet en Gran Bretaña. Para el Gobierno, la defensa del status legal del ex gobernante ponía a prueba la consolidación del régimen democrático. Pero para una proporción importante de la opinión pública internacional (y para una parte no desdeñable de la nacional), el arresto del ex presidente ponía de manifiesto la escasa voluntad demostrada por los gobiernos de la Concertación, así como determinados actores y/o estamentos de la sociedad chilena respecto de encausar a quien consideraban como el responsable de las violaciones a los 
derechos humanos durante un período relevante de su historia contemporánea. Más allá de la defensa "institucionalista" de la administración chilena y el carácter simbólico que tuvo el arresto para la puesta en marcha de instancias coercitivas efectivas en la legislación internacional, esta acontecimiento puso de manifiesto que el tema de las violaciones a los derechos de las personas durante 17 años de excepción es un asunto culturalmente pendiente en Chile.

Pese a los ingentes esfuerzos del gobierno chileno en orden a obtener la libertad del general Pinochet, ésta se concretó, finalmente, por voluntad unilateral del gobierno británico. Es difícil auscultar cuán sensible fue éste a la postura o presiones esgrimidas por la diplomacia chilena, pero es evidente que fue una dura manera de comprobar los límites del status internacional de Chile, especialmente en circuitos en los que predominan las posturas y/o los intereses de países de mayor envergadura.

\section{ALGUNAS CONCLUSIONES}

Al tenor de nuestro apretado análisis, entre 1973 y 2003 nuestro país ha vivido las más disímiles situaciones internacionales. Al comienzo del período, la situación externa de Chile puede describirse como intermedia entre el tercermundismo de un país latinoamericano "revisionista" y un no del todo claro acercamiento hacia los países socialistas. A raíz del golpe de estado y de las conductas del gobierno militar, el régimen llegó a tener algunas características de "paria" internacional, dirigido por un gobierno políticamente censurado, no sólo por sus naturales adversarios, los regímenes del "socialismo real", sino también por importantes democracias occidentales.

En ambigua relación con esta realidad, ya en el gobierno militar y durante las dos primeras administraciones de la Concertación (el gobierno de Patricio Aylwin y parte del gobierno de Eduardo Frei), el país alcanzó una peculiar reputación internacional, el "jaguar latinoamericano", réplica regional de los "tigres" o "dragones" asiáticos. La proyección de la crisis asiática de los años 1996-1997 en América Latina, combinada con factores de orden interno, socavaron esta posición. Con todo, en el contexto de las más recientes crisis de los países vecinos, todavía se mantiene la percepción internacional del "excepcionalismo" chileno, imagen diplomáticamente útil en las exitosas negociaciones de acuerdos con la Unión Europea y con los Estados Unidos en meses recientes.

Hoy en día, la administración del Presidente Ricardo Lagos está procurando combinar la política de acuerdos económicos internacionales con un reconocimiento (implícito) de la hegemonía político-estratégica de Estados Unidos. No obstante, el proceso de toma de decisiones sobre la guerra de Irak demuestra que el gobierno chileno no ha renunciado a contar con un margen, aunque reducido, de espacio autónomo para la defensa de intereses y principios políticos que considera fundamentales.

En algún momento se creó la expectativa que Chile podría unirse al selecto grupo de países desarrollados hacia el año 2010, época del Bicentenario. La ya mencionada disminución del ritmo de crecimiento económico del país, además de las persistentes brechas en materias como educación, ciencia y tecnología indican, claramente, que esto no ocurrirá. Seguirá por mucho tiempo siendo un país en desarrollo, que adolece de síntomas de estancamiento en algunos aspectos, aunque se encuentre relativamente avanzado en diversas áreas, reflejadas, por ejemplo, en los 
Informes de Desarrollo Humano del PNUD, los cuales se refieren a la sociedad chilena entre aquellas de categoría superior en lo que toca a los índices de desarrollo humano.

En los treinta años desde 1973, Chile ha recorrido -con fuertes altibajos- un sinuoso camino de apertura política, económica, social y cultural hacia el mundo. Esa trayectoria ha constituido una experiencia compleja, ciertamente incompleta y a ratos traumática, especialmente para actores que aún no están preparados para los cambios que conllevan los diversos y entrelazados procesos de apertura. Al mismo tiempo, este conjunto de experiencias ha sido enriquecedor, tanto para sucesivos gobiernos y sus funcionarios (civiles y militares), así como para empresarios, académicos, trabajadores y actores de la cultura y la sociedad civil. Para un actor pequeño como Chile, acceder a niveles más complejos de las redes interestatales y transnacionales en pleno proceso de globalización, lo obliga a poner en marcha extraordinarios esfuerzos de aprendizaje ("re-socialización"), junto a cambios en la perspectiva y en la reasignación de recursos, todo lo cual exige superar hábitos locales que tienen sus raíces en tradiciones seculares del relativo aislamiento geográfico-cultural de otras épocas.

Manfred Wilhelmy von Wolff. Profesor de relaciones internacionales y de política exterior de Chile en el Instituto de Ciencia Política/PUC y en el Instituto de Estudios Internacionales de la Universidad de Chile. Director Ejecutivo de la Fundación del Pacífico, Santiago de Chile.

(E-mail: info@funpacifico.cl)

Roberto Durán Sepúlveda. Profesor de relaciones internacionales y de negociaciones multilaterales y coordinador del programa de magíster en el Instituto de Ciencia Política/PUC.

(E-mail: rduran@puc.cl) 